\title{
Correction to: The effect of video exercise-based telerehabilitation on clinical outcomes, expectation, satisfaction, and motivation in patients with chronic low back pain
}

\author{
Fatih Özden $^{1} \cdot$ Zübeyir Sarı $^{2}$ Özgür N. Karaman ${ }^{3} \cdot$ Hüseyin Aydoğmuş ${ }^{4}$ \\ Published online: 2 October 2021 \\ (c) The Author(s), under exclusive licence to Royal Academy of Medicine in Ireland 2021
}

\section{Correction to: Irish Journal of Medical Science (2021) \\ https://doi.org/10.1007/s11845-021-02727-8}

The above article was published online with error. The Ethical number found in page 3 of the proof has been captured twice. This should be corrected to "Marmara University (No: 09. 2020.518)".

The Original article has been corrected.

Publisher's Note Springer Nature remains neutral with regard to jurisdictional claims in published maps and institutional affiliations.

The original article can be found online at https://doi.org/10.1007/ s11845-021-02727-8.

Fatih Özden

fatihozden@mu.edu.tr

1 Department of Health Care Services, Köyceğiz Vocational School of Health Services, Muğla Sitkı Koçman University, Muğla, Turkey

2 Faculty of Health Sciences, Department of Physiotherapy and Rehabilitation, Marmara University, İstanbul, Turkey

3 Physical Therapy Unit, Muğla Sıtkı Koçman University, Training and Research Hospital, Muğla, Turkey

4 Faculty of Medicine, Department of Physical Therapy and Rehabilitation, Muğla Sitkı Koçman University, Muğla, Turkey 